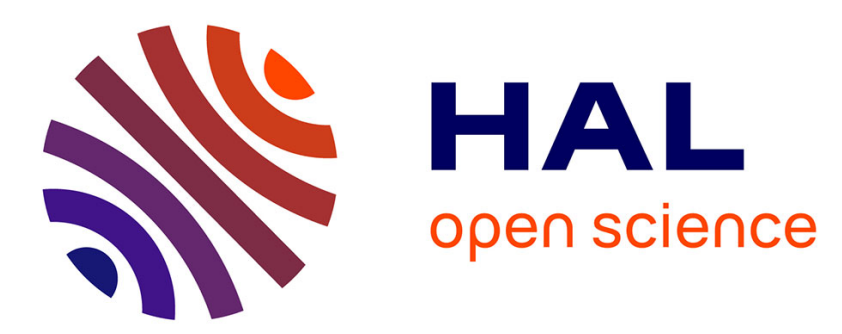

\title{
A full-scale experimental study concerning the moisture condensation on building glazing surface
}

Chi-Kien Nguyen, Cătălin Teodosiu, Frederic Kuznik, Damien David, Raluca Teodosiu, Gilles Rusaouen

\section{- To cite this version:}

Chi-Kien Nguyen, Cătălin Teodosiu, Frederic Kuznik, Damien David, Raluca Teodosiu, et al.. A fullscale experimental study concerning the moisture condensation on building glazing surface. Building and Environment, 2019, 156, pp.215-224. 10.1016/j.buildenv.2019.04.024 . hal-02106459

\section{HAL Id: hal-02106459 \\ https://hal.science/hal-02106459}

Submitted on 23 Apr 2019

HAL is a multi-disciplinary open access archive for the deposit and dissemination of scientific research documents, whether they are published or not. The documents may come from teaching and research institutions in France or abroad, or from public or private research centers.
L'archive ouverte pluridisciplinaire HAL, est destinée au dépôt et à la diffusion de documents scientifiques de niveau recherche, publiés ou non, émanant des établissements d'enseignement et de recherche français ou étrangers, des laboratoires publics ou privés. 


\author{
A full-scale experimental study \\ concerning the moisture condensation on building glazing surface \\ Chi-Kien NGUYEN ${ }^{\mathrm{a}}$, Cătălin TEODOSIU ${ }^{\mathrm{b}^{*}}$, Frédéric KUZNIK ${ }^{\mathrm{a}}$, \\ Damien DAVID ${ }^{\mathrm{c}}$, Raluca TEODOSIU ${ }^{\mathrm{b}}$, Gilles Rusaouën ${ }^{\mathrm{c}}$ \\ âniversité de Lyon, INSA de Lyon, CETHIL UMR5008 F-69621, Villeurbanne, France \\ ${ }^{\mathrm{b}}$ Faculty of Building Services and Equipment, CAMBI Research Center, \\ Technical University of Civil Engineering, Bucharest 020396, Romania \\ 'Université de Lyon, Université Lyon 1, CETHIL UMR5008, F-69622, Villeurbanne, France \\ *Corresponding author. Tel.: +40 2125246 20; fax: +40 212526880. \\ E-mail address: cteodosiu@yahoo.com (C. Teodosiu).
}

\begin{abstract}
Superficial condensation phenomena often occur on the glazed elements of buildings. As a result, the aim of this study is to put forward an experimental approach to assess the condensation rate on building glazing surface for full-scale room tests under realistic conditions. The proposed method for condensation quantification is applied in this work for surface condensation on a cold glazing $(2.90 \mathrm{~m} \mathrm{x} 2.30 \mathrm{~m})$ within a ventilated test room $(6.20 \mathrm{~m} \times 3.10 \mathrm{~m} \times 2.50 \mathrm{~m})$. We first describe the full-scale test cell, focusing then on the experimental apparatus employed for the condensation study. This is followed by the description of the methodology for the condensation rate quantification. The approach is based on image processing techniques, using condensation pictures. This allows also to reveal the mechanisms behind the condensation appearance and growth. On the other hand, the experimental data achieved by this method are compared with theoretical results based on condensation rate and heat transfer coefficient correlations available in the literature. An overall difference of up to $18 \%$ between the measured results and the theoretical results was found for the condensation rate. Consequently, the method proposed in this work leads to promising results concerning the condensation rate quantification on cold glazing within full-scale enclosures.
\end{abstract}

Keywords: Condensation; Experimental measurements; Full scale test room; Humidity; Ventilation 


\section{Introduction}

People often encounter superficial condensation phenomena in everyday life. Some of these phenomena are harmless (although they may be enjoyable, such as condensation on the surface of a glass, filled with a cold drink during a hot summer day). Other phenomena of superficial condensation lead to positive effects (e.g. latent heat recovery of water vapor in the flue gas through condensing boilers). On the other hand, there are also problems caused by condensation. Most of these problems, due to water vapor condensation, occur in buildings. In this context, research has clearly highlighted the connection between surface condensation and mold growth in buildings [1-4]. Furthermore, mold development is a major human health concern, evidently confirmed nowadays [5]. This issue has been thoroughly studied over recent years [6-8]. In addition, condensation can affect various building components (e.g. compromise the performance of thermal insulation, alter the finishing materials or even deteriorate structural components) $[9,10]$.

As a consequence, the number of studies concerning moisture in buildings has gradually increased. We can cite here several important research programs dealing with possible manifestations of moisture inside the buildings: the AIVC (Air Infiltration and Ventilation Centre) technical note 20 "Airborne Moisture Transfer" [11], the IEA (International Energy Agency) Annex 14 "Condensation and energy" [12], the IEA Annex 24 "Heat, Air and Moisture Transport" [13], and the IEA Annex 41 "Whole building heat, air, moisture response" [14]. In addition, ASHRAE (American Society of Heating, Refrigerating and Air-Conditioning Engineers) has recently added (2017) a special chapter titled "Moisture Management in Buildings" within the well-known "ASHRAE handbook: fundamentals" [15].

In fact, moisture diffusion and transport in enclosures is an extremely complex phenomenon, particularly if the interaction with heat transfer and airflow is taken into account [16]. Consequently, research in this field must investigate coupled heat-air-moisture transfers in a global manner. Common tools for studying and assessing these heat-air-moisture interactions in buildings include both numerical methods (usually multi-zone or CFD - Computational Fluid Dynamics models) and experiments (reduced-scale tests or full-scale tests). For example, Plathner and Woloszyn [17] have carried out an experimental study (using tracer gas technique) and have also developed multi-zone models for a fully furnished two-storey test house in order to assess the airborne moisture movement. They have also included humidity adsorption phenomena by indoor 
surfaces in their numerical approach. Woloszyn et al. [18] have used four commercial heat-airmoisture building simulation tools (multi-zone approach) to determine the performance of different moisture management strategies concerning the indoor air quality and energy efficiency for a real one-storey test building with two rooms. It is also worth mentioning the studies undertaken by Van Belleghem and Steeman [19-22] dealing with coupled CFD - HAM (heat-airmoisture) models and their experimental validation. This technique is capable of associating indoor air movement with heat and moisture transfer phenomena in solids. On the other hand, Tariku et al. [23] have proposed a holistic HAM model integrating building envelope, indoor air, mechanical systems, as well as sensible and latent heat generated by internal sources. Qin [24] has used a coupled model (based on multi-zone hygrothermal-airflow approach, associated with the heat and moisture transfer in the building envelope) in order to assess the humidity effect on indoor air quality and building energy consumption in different climates. Feng et al. [25] have also studied the moisture propagation in a multi-zone space, using a moisture-energy-airflow model of building behavior (in terms of energy consumption and indoor air quality). Pu et al. [26] have developed a CFD model for humidity distribution in enclosures and they have compared the numerical results with experimental data obtained by means of an environmental chamber $(1.00 \mathrm{~m} \times 1.00 \mathrm{~m} \times 1.50$ $\mathrm{m})$.

Despite this growing interest concerning the study of heat-air-moisture transfer phenomena at the whole-building scale, there is no special focus toward the surface condensation problems. In this context, research dealing with superficial condensation in buildings is still limited. For example, Cho et al. [27] have studied the condensation risk throughout the year for an office building in warm and wet climate, based on multi-zone numerical models (TRNSYS simulation coupled with TRNFLOW). Nevertheless, the condensation risk assessment was simply determined using the correlation between the surface temperature and the dew-point temperature of air. Based on the results, the authors proposed three indicators in order to evaluate the condensation risk: condensation ratio, condensation frequency and condensation risk throughout the year [27]. Liu et al. [28] have accomplished experimental and CFD studies on surface condensation in rooms but their test chamber was at reduced-scale $(1.22 \mathrm{~m} \times 1.21 \mathrm{~m} \times 1.50 \mathrm{~m})$. Gong et al. [29] have also employed the CFD technique in order to examine the problem of moisture condensation on building elements but this has been only fulfilled by calculating the temperature differences between the inner wall surface and the air dew point near the wall. The same elementary method 
relying on the dew point has been adopted in study [30] - also based on CFD simulations, in order to determine the risk of moisture condensation on the interior surface of buildings in high humidity climate. Ma et al. [31] have developed a theoretical model for predicting wall condensation in rooms. Unfortunately, the results of this model have been compared with full-scale tests (experimental chamber $4 \mathrm{~m}$ long, $3 \mathrm{~m}$ wide, and $2.5 \mathrm{~m}$ high) only for conditions of no condensation. The theoretical model has been compared merely with CFD results under condensation conditions. Further, the results available in [31] were only in terms of qualitative condensation predictions (condensing areas at different time steps).

On the other hand, with the advanced techniques available nowadays, the condensation quantification might be achievable using high-definition image recording technique. In fact, this is the main objective of this study: the development of an experimental method to quantify the condensation on large glazing surfaces (characteristic for real buildings), under realistic conditions (e.g. ventilated rooms). For this reason, the proposed method for condensation quantification is applied in this work for surface condensation on a cold glazing $(2.90 \mathrm{~m} \times 2.30 \mathrm{~m})$ within a ventilated test room $(6.20 \mathrm{~m} \times 3.10 \mathrm{~m} \times 2.50 \mathrm{~m})$.

We initially present the experimental set-up (including the metrology and the experimental protocol), followed by the detailed description of the method used for the quantification of the condensation rate. The results are then presented, compared, and discussed, together with correlations available in the literature for computing the condensate mass flow rate.

Finally, it is worth mentioning that global analysis of heat-air-moisture transfer phenomena (including condensation) in buildings has continuously been one of the main research field of the authors [32,33]. In fact, this study is part of an extensive research project of the authors aimed to accomplish experimental and numerical analyses for humid air in ventilated rooms, including water vapor surface condensation [34].

\section{Experimental set-up}

\subsection{MINIBAT test room}

The experimental investigation was conducted in a full-scale test cell MINIBAT, whose environment is entirely controllable. MINIBAT is located at the CETHIL laboratory - INSA de Lyon, France (Figure 1). It consists of three distinct volumes: a test room where experiments are carried out, a thermal buffer zone which allows maintaining stable and reproducible boundary 
conditions and a climatic chamber which simulates the outdoor temperature. The South façade, which is in contact with the climatic chamber, is a $1.2 \mathrm{~cm}$ thick laminated glazing $(\mathrm{W} \times \mathrm{H}=2.90$ $\mathrm{m} \times 2.30 \mathrm{~m}$ ). The surface-to-surface thermal resistance is $\mathrm{R}=0.012 \mathrm{~m}^{2} \mathrm{~K} / \mathrm{W}$. A network of 180 Pt100 probes (measurement error: $\pm 0.2^{\circ} \mathrm{C}$ ) is implemented on both external and internal sides of six walls of the test room to measure their temperature [35].

The air is introduced into the test room via an air diffuser located on the ceiling; the air jet issued from the diffuser is vertical and descendant. The air is extracted through two air exhausts located on the North wall. This disposition increases the homogeneity of the air distribution within the test room. The supply air temperature, humidity and the airflow rate are controlled by means of a closed-loop air handling unit. The air temperature and relative humidity measurements are carried out using Pt100 probes (accuracy: $\pm 0.1^{\circ} \mathrm{C}$ ) and Sensirion SHT75 probes (accuracy: $\pm 1.8 \%$ ), respectively [35]. The airflow rate is measured by a propeller flowmeter (accuracy: $\pm 0.5 \mathrm{~m}^{3} / \mathrm{h}$ ) [35].

We have designed and programmed a mobile robot (Figure 1), equipped with sensors, in order to measure the indoor air velocity, temperature and humidity fields. The following sensors were used to perform the measurements [35]: air velocity - ThermoAir64 (Schiltknecht) omnidirectional hot-sphere anemometers (measurement range: $0.01-1 \mathrm{~m} / \mathrm{s}$ with an accuracy of \pm 1 $\%$ full-scale and $\pm 1.5 \%$ reading value); air temperature $-25 \mu \mathrm{m}$ diameter type $\mathrm{K}$ thermocouples (absolute accuracy: $\pm 0.06^{\circ} \mathrm{C}$ on the mean measured value); air relative humidity - SHT75 (Sensirion) probes (accuracy: $\pm 1.8 \%$ ). A detailed description of the test cell and the mobile robot can be found in $[35,36]$. 


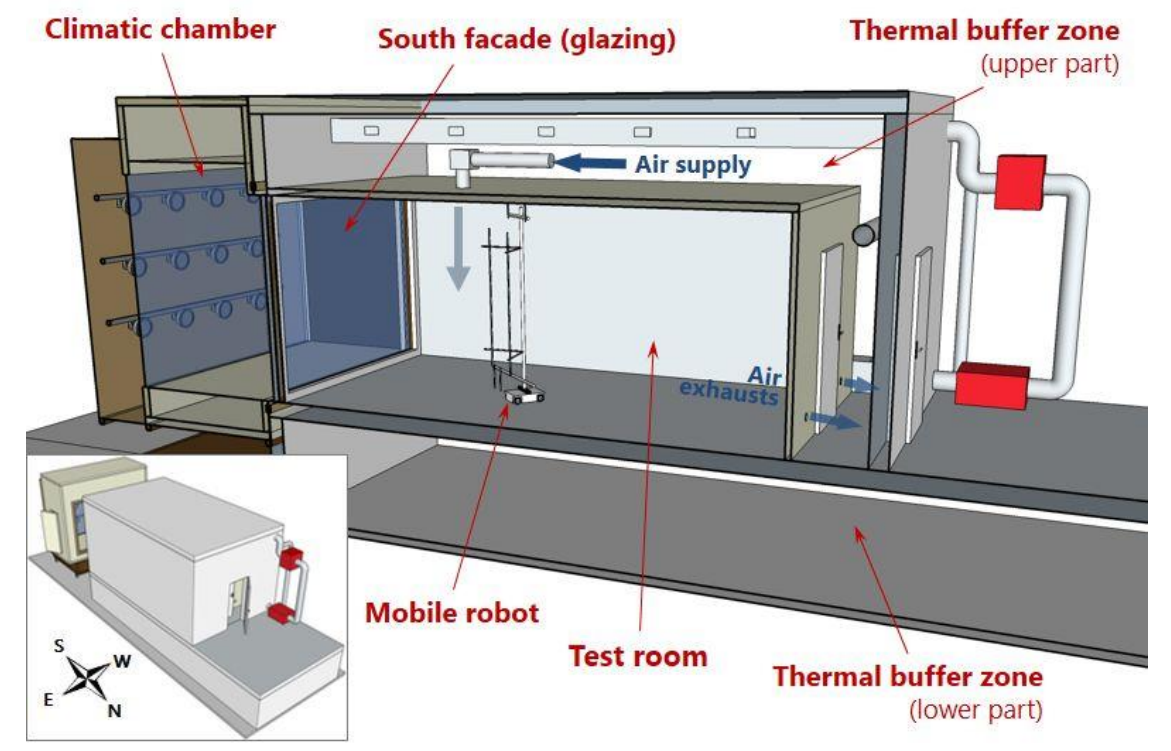

Figure 1. Scheme of MINIBAT test room

\subsection{Experimental apparatus for the condensation study}

Dropwise condensation appears on the inner surface of the South glazing when the temperature in the climatic chamber is sufficiently cold, and when the relative humidity in the test cell is sufficiently high. Hence, we have installed a digital camera inside the test cell, at the South-East lower corner, to capture pictures of condensate droplets on the glazing (Figure 2).

The camera is a Nikon D810 digital single-lens reflex (DSLR). Its image sensor has a size of $35.9 \times 24.0 \mathrm{~mm}$ and a resolution of $7360 \times 4912$ pixels (36.3 million effective pixels). The ratio pixel/mm is therefore equal to approximately $205 \mathrm{px} / \mathrm{mm}$ in both directions. The camera is equipped with a lens dedicated to macro-photography. It is a Nikon $105 \mathrm{~mm} \mathrm{f/2.8} \mathrm{with} \mathrm{a}$ reproduction ratio of $1: 1$. This ratio means that the size of the image on the sensor is identical to the size of the captured object. The lens is equipped with 4 synchronized speed-light flash system designed especially for macro-photography (Figure 2). The camera is mounted on a tripod and is set to be perpendicular to the glazing. To guarantee the $1: 1$ reproduction ratio, the glazing must be at the minimum focus distance from the camera, i.e. $314 \mathrm{~mm}$ from the sensor. As a result, we use a micrometric positioning sliding plate, installed between the tripod and the camera (Figure 2), to position precisely the camera. The glazing area being captured by the camera has the dimension of the camera image sensor, which is $35.9 \mathrm{~mm} \times 24.0 \mathrm{~mm}$. 


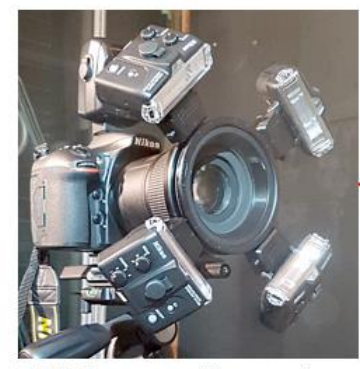

Digital camera with macro lens and speed-light flash system

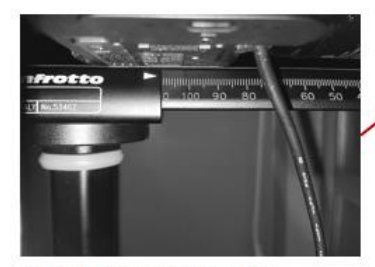

Micrometric positioning sliding plate
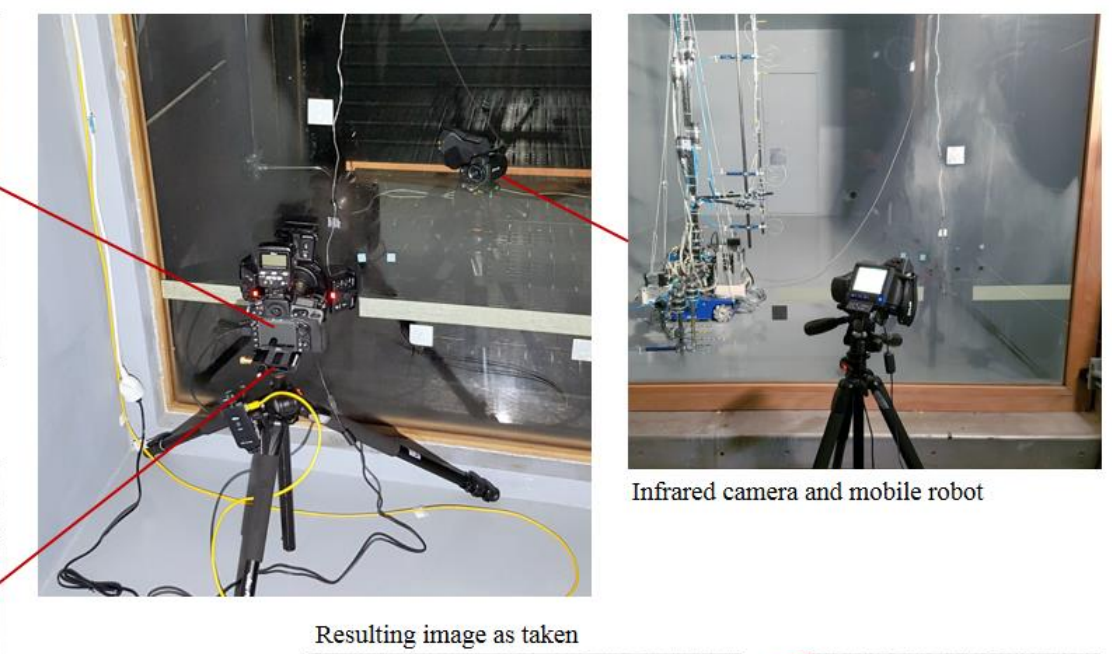

Infrared camera and mobile robot

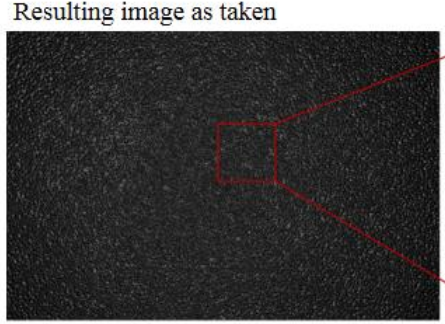

$35.9 \times 24 \mathrm{~mm}$

Figure 2. Condensation study metrology

To monitor the surface temperature of the corresponding glazing area during the condensation test, an infrared (IR) camera is set up inside the climatic chamber (Figure 2). We used a FLIR T420bx IR camera (absolute accuracy: $\pm 2^{\circ} \mathrm{C}$ ). Despite its advantageous characteristic of wholefield measurements, the infrared measurement technique is constrained by its high uncertainty [37], and by its sensitivity to the reflected flux radiation [38]. Indeed, the IR camera is used to measure the surface temperature of the glazing, but the radiation received by the IR camera also comes from environmental radiation reflected by the glazing. Consequently, a procedure was applied to quantify the reflected part of the radiation: four small pieces of aluminum foil tape were fixed at the four corners of the capturing area; they were used as correction materials for determining the real temperature of the glazing surface [35].

\subsection{Experimental protocol}

A full test includes a preliminary transient phase, which is needed to reach the initial steady conditions, and the test phase during which the condensation occurs.

During the preliminary transient phase, we adjust the set points to reproduce winter conditions: cold temperature in the climatic chamber and hot air supply. The humidity content of the supplied 
air is sufficiently low to avoid condensation at the window. Three days are required to reach stable initial conditions.

At the beginning of the test phase, we increase the humidity set-point for the supply air, and we start recording pictures with the DSLR and the IR cameras. The humidity content of the air increases sufficiently to initiate the condensation process on the cold window.

The temperature acquisition time step for the IR camera is fixed at 5 minutes. The acquisition time step for the DSLR camera is fixed at 60 seconds.

Concerning the indoor air metrology, the mobile robot is kept immobilized. It is set up close to the glazing (Figure 2) in order to record the evolution of the air velocity, temperature and humidity over time. The data recording time step is set at 60 seconds. The data recording begins 15 minutes before setting up the test condition [35].

\section{Methodology for the condensation rate quantification}

The post-treatment of the experimental data aims to determine the condensation rate over the glazing surface from the series of condensation pictures using image processing techniques. The experimental data obtained by this method will be also compared with theoretical results issued from two analytical models found in the literature.

\subsection{Theoretical considerations}

During the condensation process, water vapor form little droplets that grow on the glazing surface. To determine experimentally the condensation rate, we evaluate the total mass of water vapor condensed on the glazing surface for each picture. This total mass is the sum of the droplets

mass on this area. The mass of a single droplet is: $m_{d}=\rho_{l} V_{d}$. The water density at the atmospheric pressure $\rho_{l}$ is given in tables as a function of the water temperature [39]. In addition, we suppose that each droplet has the shape of a truncated sphere (Fig. 3). In this case, the volume of a droplet $V_{d}$ can be determined by the following equation [40]:

$$
V_{d}=\frac{\pi r_{d}^{3}}{3}\left(2-3 \cos \theta+\cos ^{3} \theta\right)
$$

where $\theta\left(^{\circ}\right)$ is the contact angle between the droplet and the glazing surface, and $r_{d}(\mathrm{~m})$ is the radius of the droplet (Figure 3). 
The contact angle $\theta$ depends only on the surface tension of the glazing surface material, the properties of the liquid, and the properties of the vapor. As a result, the contact angle $\theta$ is assumed to be constant, regardless of the droplet size $r_{d}$, the surface temperature $T_{w}$ and vapor temperature $T_{\text {vap }}$ (Figure 3). The procedure for measuring $\theta$ is described in section 3.2.

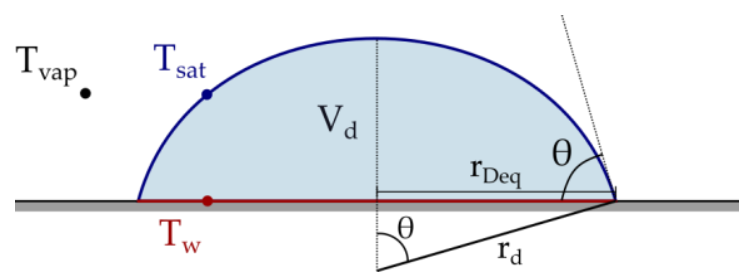

Figure 3. Volume, contact angle and radius of a single droplet condensed water vapor

On the other hand, the radius of the droplet $r_{d}$ can be determined as follows:

$$
r_{d}=\frac{r_{D e q}}{\sin \theta}=\frac{1}{\sin \theta} \sqrt{\frac{S_{d}}{\pi}}
$$

where $r_{D e q}(m)$ is the equivalent radius and $S_{d}\left(m^{2}\right)$ is the contour area of the droplet.

The condensation pictures capture only the footprint of the droplet, i.e. the shape of the area in which the droplet is in contact with the glazing surface (for an ideal droplet, the footprint is a disk with the radius $r_{D e q}$ ).

The droplet contour area in Equation (2) is determined using image processing techniques, based on condensation pictures. This procedure is described in section 3.3.

\subsection{Measurement of the droplet contact angle}

Since the contact angle does not depend on the experimental conditions, it was measured separately. For this evaluation, we used a sample of the glazing installed in MINIBAT. We cleaned the glazing sample in the same way that we cleaned MINIBAT's glazing. We poured a few droplets of water on the glazing sample. We put the glazing sample vertically, and we took pictures on the side of the glazing sample to capture the lateral shape of the droplets. The contact angle was computed using the "half-angle method" (Figure 4.a) [41]. These procedures were repeated several times to determine an averaged value of the contact angle. In the example of the Figure 4.b, the left image is the raw image as taken while the right image is the image processed using the edge detection technique. The edges detected are represented by the light parts and the rest are dark 
parts. Based on the Figure 4.b, the contact angle is approximately $59.5^{\circ}$. This value is in agreement with [42]. In general, without surface treatment, a contact angle smaller than $90^{\circ}$ should be obtained.

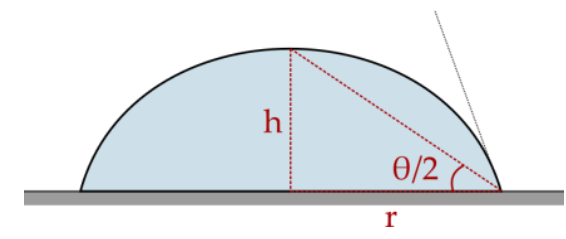

(a) Half-angle method

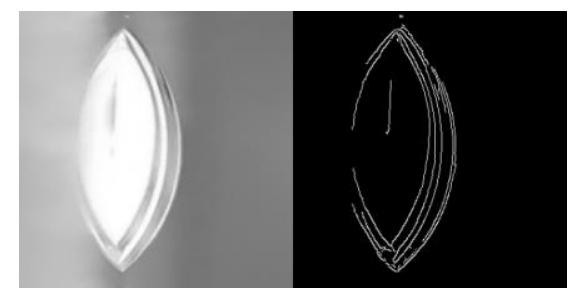

(b) Example of the droplet captured

Figure 4. Determination of the contact angle

\subsection{Measurement of the droplet footprint radius}

The droplets do not have exactly the shape of a perfect truncated sphere because of the droplet merging. In addition, the droplets footprint does not have the shape of a perfect disk. Nevertheless, assuming that Equations (1) and (2) are still valid, the droplets contour area and droplets radius are determined using computerized methods, based on image processing techniques. This consists of successive steps of transformation and analysis of condensation pictures, in order to find the droplet contours and thus to assess the total volume of the droplets, using the Equations (1) and (2).

For a better illustration, an example of a captured image is given in Figure 5. The image on the left is the raw image as captured, whose dimensions are $35.9 \times 24.0 \mathrm{~mm}^{2}$. The right image shows a cropped and zoomed area of $5.0 \times 5.0 \mathrm{~mm}^{2}$. We use this sample to illustrate the technique used for image processing. The image processing method for finding and analyzing the droplet contours is based on Python environment, along with the OpenCV package for Python, and include therefore the following steps (illustration of these steps is given in Figures 6.a to 6.d): 


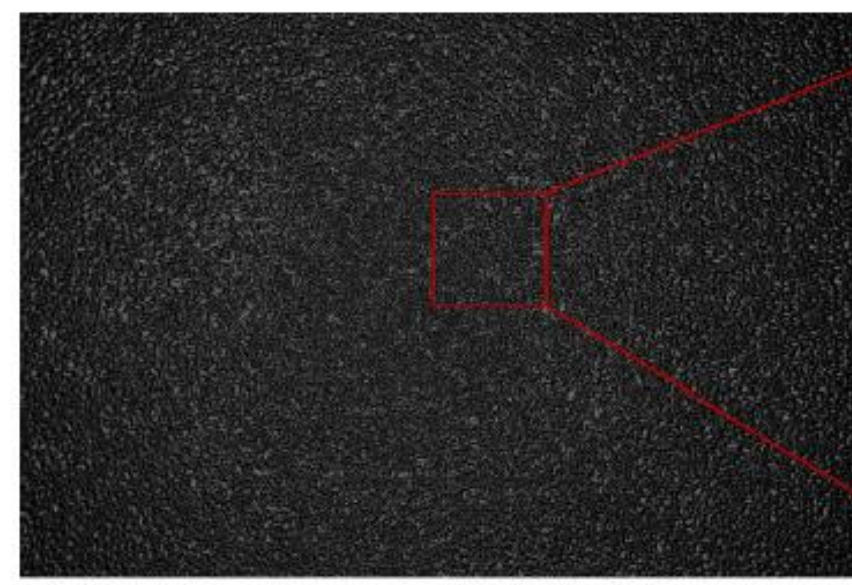

$35.9 \times 24 \mathrm{~mm}$

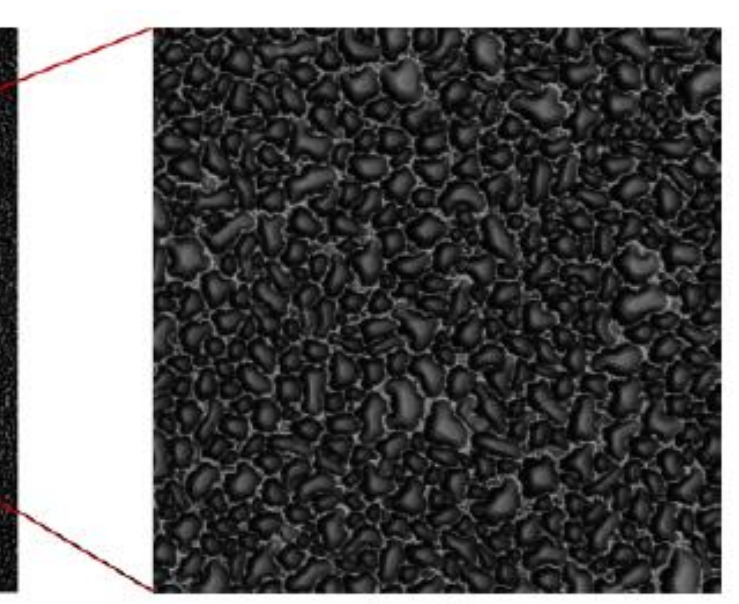

$5 \times 5 \mathrm{~mm}$

Figure 5. Example of captured image for droplets on the cold glazing

1. Histogram equalization (Figure 6.a): the raw image has a non-homogeneous contrast, i.e. a brighter zone in the center and a darker zone in the corner. This vignette effect is due to the flashlights system during the capture. Therefore, the histogram equalization method allows to adjust the image global contrast so that areas of lower local contrast can gain a higher contrast [43]. The resulting image, having its histogram equalized, shows a clear difference in terms of global contrast compared to the raw image.

2. Noise filtering (Figure 6.b): a filter is applied to reduce the noise content, which could potentially be detected later as droplets edges. Nevertheless, since high frequency contents comprise both edges and noises, a simple Gaussian low-pass filter would help removing noises but also undesirably blurring the edges. Consequently, the bilateral filtering [44] is employed. This technique is basically a non-linear Gaussian filter, which demonstrates its highly effectiveness in noise removal while preserving sharp edges [45].

3. Image thresholding (Figure 6.c): the filtered image goes through the thresholding process. This technique is used to reduce grayscale images into binary images, i.e. images having only two levels: black and white. This process is essential for increasing the accuracy of the next step, which is the contours finding. There are several methods for "thresholding" an image [46]:

- the simplest one is to assign an unique "user-defined" value as threshold value for the whole image - the "Global (or Simple) Thresholding";

- when the illuminating conditions vary from an image to another, an adaptive thresholding method might be more relevant; for this, the threshold value is calculated locally for small regions 
of the image while taking into account the neighborhood region. The OpenCV package proposes two adaptive threshold algorithms:

(1) "Adaptive Mean Thresholding": the threshold value $\mathrm{T}(\mathrm{x}, \mathrm{y})$ at an image coordinate $(\mathrm{x}, \mathrm{y})$ is a mean of the "user-defined" area size in the neighborhood;

(2) "Adaptive Gaussian Thresholding": the threshold value $\mathrm{T}(\mathrm{x}, \mathrm{y})$ is a weighted sum (crosscorrelation with a Gaussian window) of the "user-defined" area size in the neighborhood.

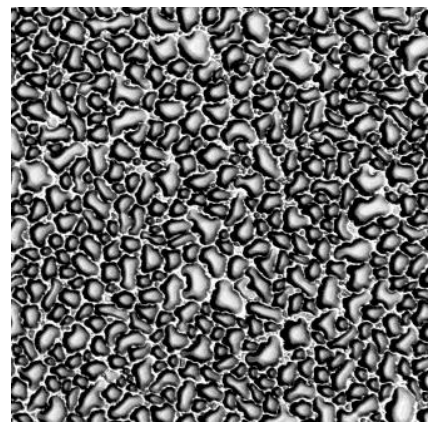

(a) Histogram equalization

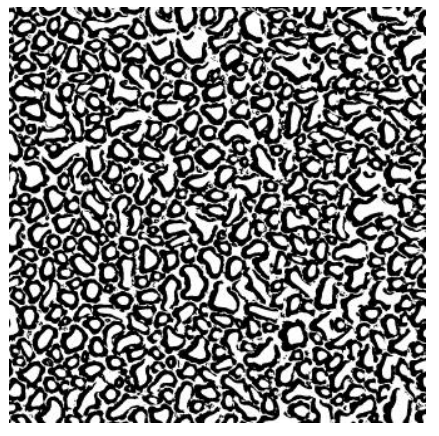

(c) Image thresholding

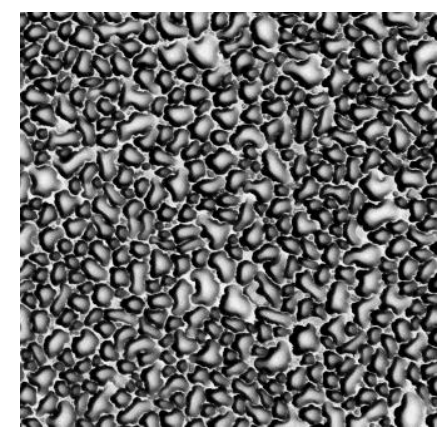

(b) Bilateral filtering

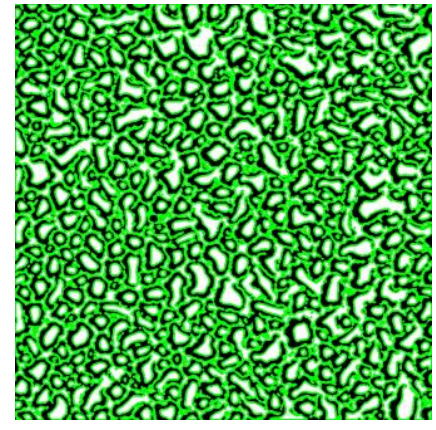

(d) Contours finding

Figure 6. Image processing steps for droplets contours finding

It is worth mentioning that in the case of "bimodal" images, i.e. images whose histogram distribution possesses two peaks after being equalized (Figure 7), the Otsu's method appears to be the most accurate and efficient [46,47]. This "binarization algorithm" automatically calculates the threshold value, based on the bimodal image histogram, as the middle value between the two peaks. Unfortunately, the Otsu's method has proven to be the less effective here, because the images in our case do not have a bimodal distribution.

Consequently, we chose to use a combination of two adaptive thresholding methods for the binarization step: "Adaptive Mean Thresholding" and "Adaptive Gaussian Thresholding". More information on applying this methodology for the images used in this study is given in [35]. 


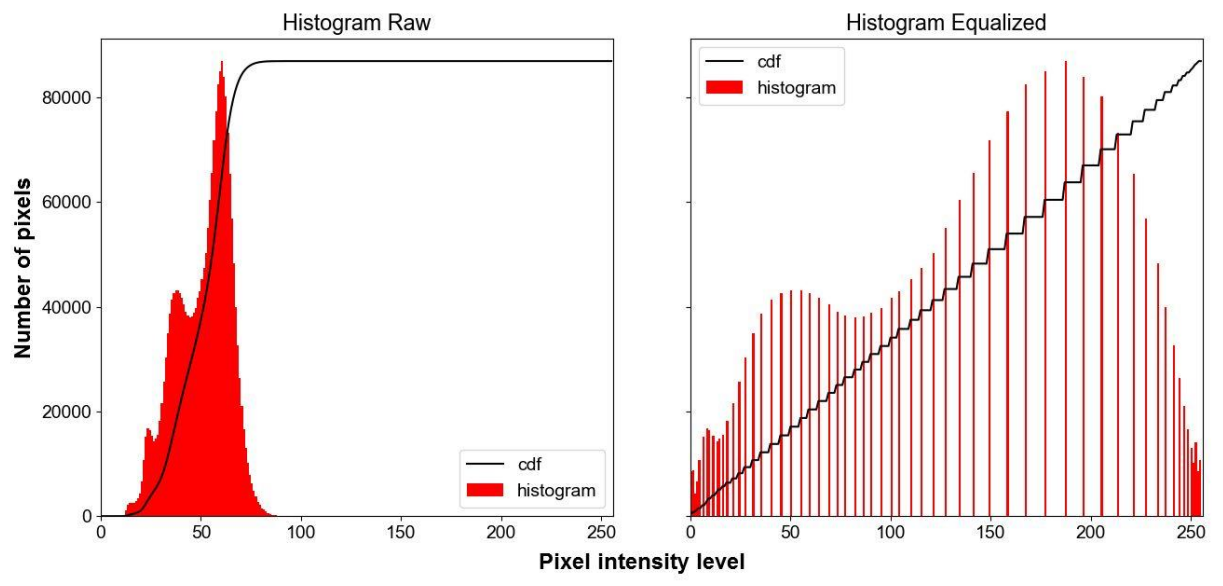

Figure 7. Histogram equalization of bimodal images

4. Contours finding (Figure 6.d): the final step consists in finding all the possible contours in the given image [48]. The contours detected are colored in green color for a better visualization. Once these contours retrieved, the following information can be extracted: the number of contours detected that correspond to the total number of droplets; the area and the equivalent radius of each droplet.

As a result, using Equation (2), we can determine the radius of each drop of condensate.

Finally, we can now calculate, based on Equation (1), the volume of each droplet of condensate and, implicitly, its mass.

\subsection{Condensation rate and heat transfer coefficient correlations}

The condensation rate $\dot{m}\left(\mathrm{~kg} / \mathrm{m}^{2} \mathrm{~s}\right)$, the overall condensation heat transfer rate $q_{\text {tot }}\left(\mathrm{W} / \mathrm{m}^{2}\right)$, and the condensation overall heat transfer coefficient $h_{\text {tot }}\left(\mathrm{W} / \mathrm{m}^{2} \mathrm{~K}\right)$ are related by the following equation:

$$
\dot{m}=\frac{q_{t o t}}{h_{l v}}=\frac{h_{t o t}\left(T_{s a t}-T_{w}\right)}{h_{l v}}
$$

where $h_{l v}(\mathrm{~J} / \mathrm{kg})$ is the latent heat of condensation, $T_{\text {sat }}\left({ }^{\circ} \mathrm{C}\right)$ is the vapor dew point and $T_{w}\left({ }^{\circ} \mathrm{C}\right)$ is the glazing surface temperature. The value of the latent heat of condensation was determined using a temperature-dependent equation [49]:

$$
h_{l v}(T)=2500.8-2.36 T+0.0016 T^{2}-0.00006 T^{3} \quad(\mathrm{KJ} / \mathrm{kg})
$$


To predict the overall heat transfer coefficient during the condensation process, Griffith [50] (as mentioned by [40]) recommended the following correlation:

$$
h_{t o t}= \begin{cases}51104+2044 . T_{\text {sat }} & \text { if } T_{\text {sat }}<100^{\circ} \mathrm{C} \\ 255510 & \text { if } T_{\text {sat }}>100^{\circ} \mathrm{C}\end{cases}
$$

This correlation is valid only when the fluid is water vapor (or steam) and for dropwise condensation.

Kim et al. [51] also developed a mathematical model to determine the overall heat transfer coefficient. Their correlation depends on the droplet size distribution and the droplet contact angle. As a result, the overall heat transfer coefficient is obtained by integrating the heat transfer coefficient through a single droplet over the droplet size distribution:

$$
h_{t o t}=2 \pi \int_{r_{\min }}^{r_{\max }} \frac{1}{3 \pi \cdot r_{\max }}\left(\frac{r_{d}}{r_{\max }}\right)^{\frac{-2}{3}} \frac{1-r_{\min } / r_{\max }}{\frac{r_{d} \cdot \theta}{2 \lambda_{l}}+\frac{1}{h_{i}(1-\cos \theta)}} d\left(r_{d}\right)
$$

where $r_{\max }(\mathrm{m})$ is the droplet fall-off radius, $r_{\min }(\mathrm{m})$ is the minimum droplet radius which allows

the droplet growth, $\lambda_{l}(\mathrm{~W} / \mathrm{mK})$ is the liquid thermal conductivity and $h_{i}\left(\mathrm{~W} / \mathrm{m}^{2} \mathrm{~K}\right)$ is the vaporliquid interfacial heat transfer coefficient. The minimum droplet radius $r_{\text {min }}$ is defined as follows [40]:

$$
r_{\min }=\frac{2 \sigma_{l} T_{v a p}}{\rho_{l} h_{l v}\left(T_{v a p}-T_{w}\right)}
$$

where $\sigma_{l}$ is the surface tension of the condensed liquid and $\rho_{l}$ is the condensed liquid density.

\section{Results and discussion}

It should be noted that five tests have been undertaken to ensure the reproducibility of the experimental data. The results of only one test are presented and discussed in detail hereafter. First, we present the experimental conditions and the indoor air evolution. Then, we present and discuss the results of the condensation qualification and quantification, i.e. the condensation growth mechanism and the condensation rate (based on the method described above).

\subsection{Experimental conditions}


The supply air conditions and the boundary conditions were measured during the whole duration of the test. They are summarized in Tables 1 and 2 .

Table 1 presents the characteristics of the supply air. It can be noticed that the airflow rate and the air temperature remained unchanged during the test. On the other hand, the air specific humidity increased from an initial value of $9.06 \mathrm{~g} / \mathrm{kg}$ to $14.07 \mathrm{~g} / \mathrm{kg}$.

Table 1. Supply air conditions: $\mathrm{Q}_{0}$ - airflow rate $\left(\mathrm{m}^{3} / \mathrm{h}\right) ; \mathrm{T}_{0}-$ air temperature $\left({ }^{\circ} \mathrm{C}\right)$; $\mathrm{r}_{0}$ - air specific humidity $(\mathrm{g} / \mathrm{kg}) ; \mathrm{RH}_{0}-$ air relative humidity $(\%)$.

\begin{tabular}{lcccc}
\hline & $\begin{array}{c}\mathbf{Q}_{\mathbf{0}} \\
{\left[\mathbf{m}^{\mathbf{3}} / \mathbf{h}\right]}\end{array}$ & $\begin{array}{c}\mathbf{T}_{\mathbf{0}} \\
{\left[{ }^{\circ} \mathbf{C}\right]}\end{array}$ & $\begin{array}{c}\mathbf{r}_{\mathbf{0}} \\
{[\mathbf{g} / \mathbf{k g}]}\end{array}$ & $\begin{array}{c}\mathbf{R H}_{\mathbf{0}} \\
{[\mathbf{\%}]}\end{array}$ \\
\hline Initial conditions & 150.0 & 28.00 & 9.06 & 38.6 \\
\hline Test conditions & 150.0 & 28.01 & 14.07 & 59.5 \\
\hline
\end{tabular}

Table 2 shows the internal surface temperatures of the walls, as well as the air temperatures in the test room (average value of temperature measurements carried out by robot probes), the climatic chamber and the thermal buffer zone during the experiment.

Table 2. Boundary conditions: temperature on internal wall surfaces and air temperature within the test cell $\left({ }^{\circ} \mathrm{C}\right)\left(\mathrm{T}_{\mathrm{amb}}\right.$ - test room air temperature; $\mathrm{T}_{\mathrm{cc}}$ - climatic chamber air temperature; $\mathrm{T}_{\mathrm{tbz}}-$ thermal buffer zone air temperature)

\begin{tabular}{ccccccc|ccc}
\hline & Ceiling & Floor & $\mathbf{S}$ & $\mathbf{N}$ & $\mathbf{E}$ & $\mathbf{W}$ & $\mathbf{T}_{\mathbf{a m b}}$ & $\mathbf{T}_{\mathbf{c c}}$ & $\mathbf{T}_{\text {tbz }}$ \\
\hline Mean value & 21.4 & 21.1 & 15.3 & 20.6 & 20.5 & 20.5 & 21.2 & 7.6 & 21.4 \\
\hline
\end{tabular}

\subsection{Indoor moist air evolution}

As previously mentioned, the mobile robot (equipped with sensors for air velocity, temperature and humidity) has been employed for the indoor air metrology (the device was placed close to the glazing - see Figure 2). Figure 8 shows the evolution of air mean velocity, temperature and relative humidity at different room heights (from 0.03 to $2.00 \mathrm{~m}$ ).

The mean air velocity is measured at six heights $(0.12 \mathrm{~m}$ and from 0.50 to $2.00 \mathrm{~m})$. It can be noticed that almost all recorded values are below $0.2 \mathrm{~m} / \mathrm{s}$. The mean air temperature and air humidity are measured at twelve heights, divided in two profiles: a central profile ( 0.50 to $2.00 \mathrm{~m})$ 
and a near-floor profile $(0.03$ to $0.15 \mathrm{~m})$. There is a temperature stratification: the mean air temperature increases approximately by $2^{\circ} \mathrm{C}$ between the floor and the room central profile and by $1^{\circ} \mathrm{C}$ within the near-floor profile.
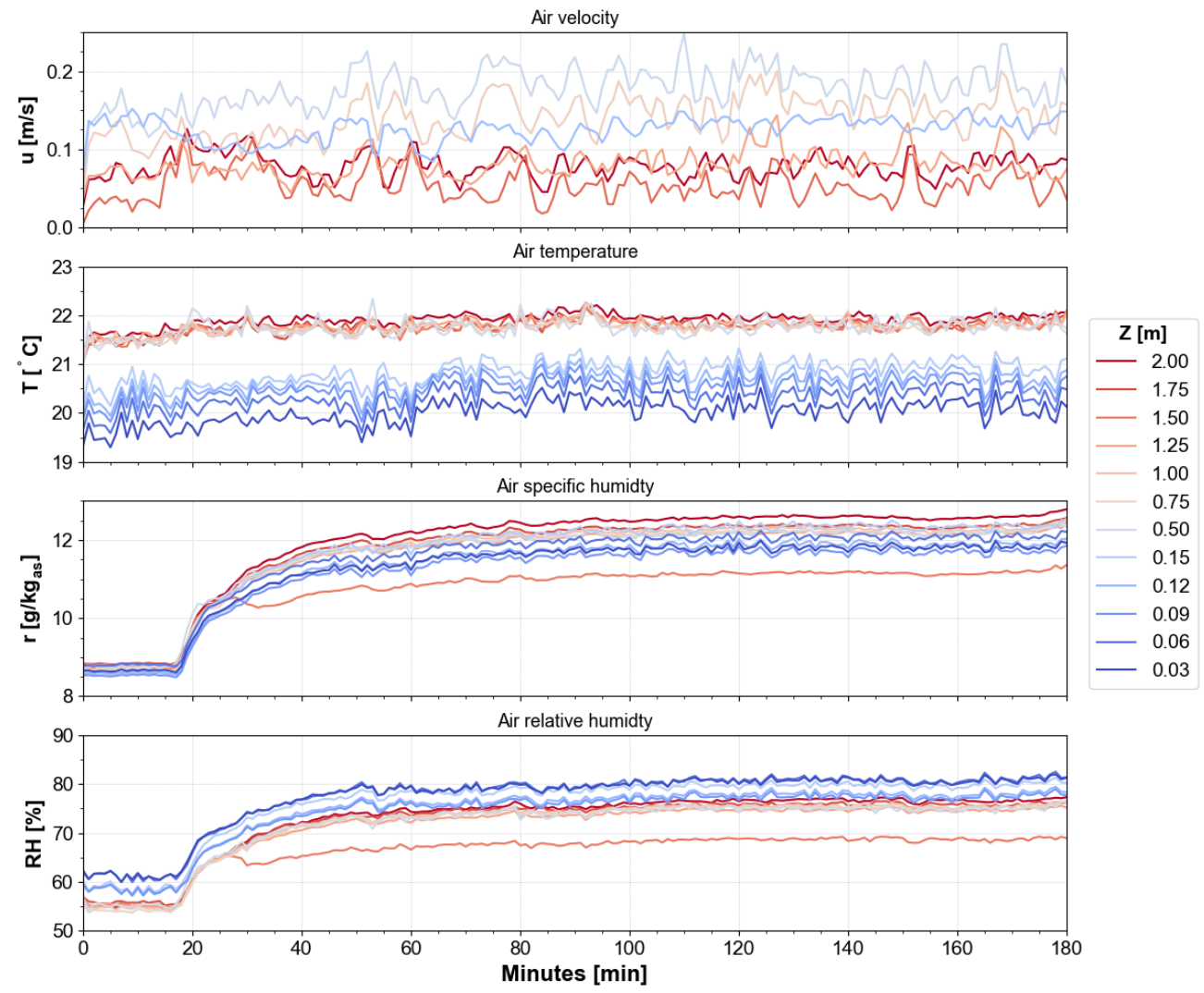

Figure 8. Evolution of the indoor moist air parameters (before and during the "condensation test")

The last two graphs (Figure 8) present the evolution of the air specific humidity and relative humidity. As soon as the air supply humidity system is switched on, the indoor air humidity level starts to increase. This transient regime lasts for approximately 40 minutes. After this, the air humidity varies from $11.5 \mathrm{~g} / \mathrm{kg}$ to $12.5 \mathrm{~g} / \mathrm{kg}$ between the floor and the top of the room, during the new established quasi-steady state regime. This stratification can be reasonably explained by the injection of water vapor in the test room, which reduces the moist air density. It can be noticed that the humidity sensor at $Z=1.5 \mathrm{~m}$ seems to be defective since its recorded values differ largely from the others; thus it was excluded from the data analysis.

\subsection{Vapor dew point and glazing surface temperature}


Once the moist air temperature and humidity are known, we can determine the vapor partial pressure and dew point. Five consecutive temperature profiles $(Z=0.09-0.75 \mathrm{~m})$ shown in Figure 8 were averaged to obtain a representative moist air temperature. The same average process was applied for the air specific humidity. Based on the air specific humidity and the atmospheric pressure, the partial pressure of the water vapor and the corresponding dew point were determined, using classic psychrometric formulas.

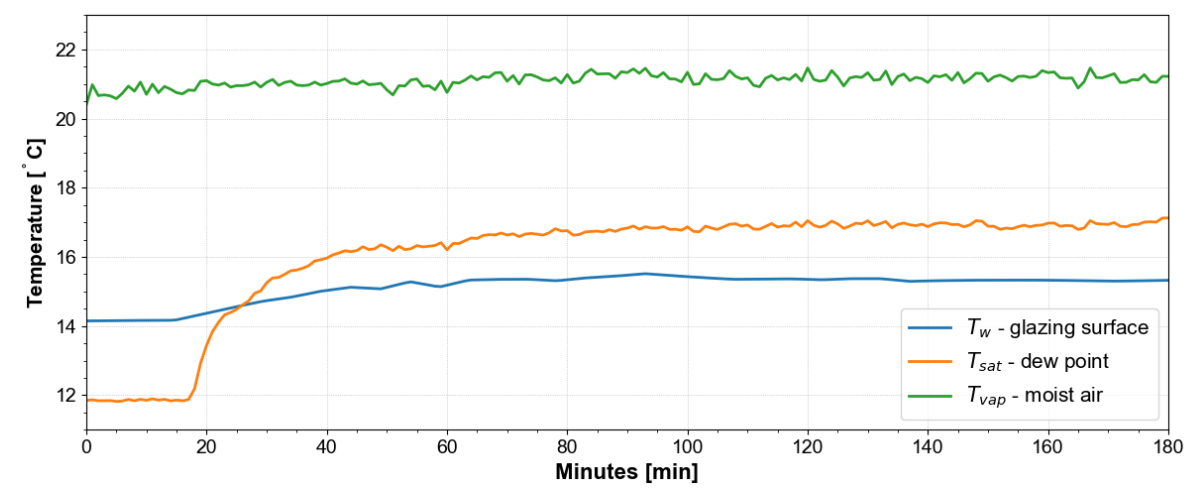

Figure 9. Temperature evolution of the moist air, the dew point and the glazing surface

The evolution of the moist air temperature, the corresponding dew point and the glazing surface temperature during the test are given in Figure 9. The moist air temperature is quasi-stable over time. The dew point remains at about $12{ }^{\circ} \mathrm{C}$ during the initial test conditions. Due to the increase in air humidity (i.e. the water vapor content) during the "condensation tests", the corresponding dew point also begins to increase at around $16.5^{\circ} \mathrm{C}$. In addition, it can be observed that the glazing surface temperature rises from approximately $14^{\circ} \mathrm{C}$ to $15.3^{\circ} \mathrm{C}$, as a result of an increased heat transfer coefficient during the condensation process.

\subsection{Condensation growth mechanism}

Figure 10 presents a series of images captured over time, which clearly show the formation, the growth, the coalescence and the fall-off and the re-nucleation of droplets along the glazing. It should be noted that all the images in Figure 10 are not raw images. These images were "equalized", according to the method described above, in order to ensure a better visualization.

In the beginning $(\mathrm{t}=0)$, droplets form at nucleation sites at the same time, with a very small initial radius. Their initial size is so small that the camera is not able to properly do an objectfocus. As a result, the vignetting effect (darker zone at the image periphery) can be observed. It is 
actually the failure of the synchronization between the out-of-focus shooting and illuminating. At this early stage, the droplets grow mainly by direct deposition of condensed saturated vapor onto the glazing surface.

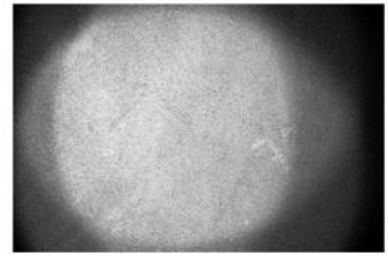

(a) $t=0$

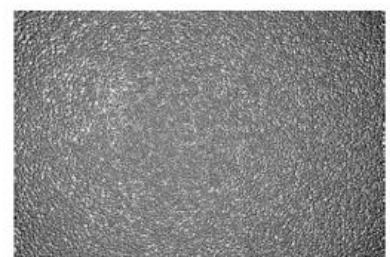

(d) $t=35 \mathrm{~min}$

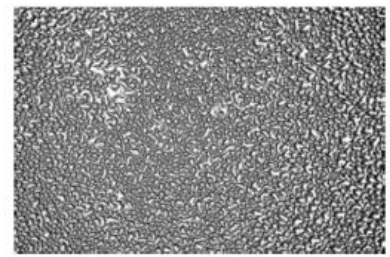

(g) $t=75 \mathrm{~min}$

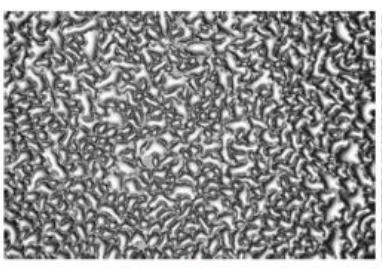

(j) $t=150 \mathrm{~min}$

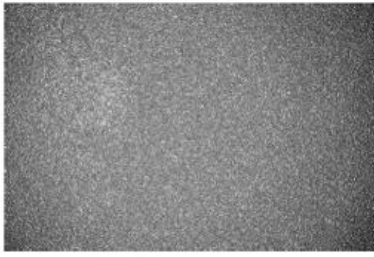

(b) $t=15 \mathrm{~min}$

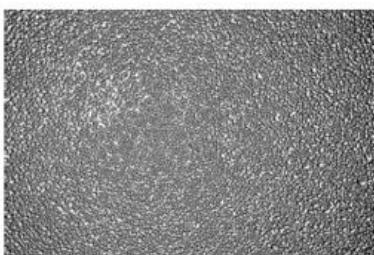

(e) $t=45 \mathrm{~min}$

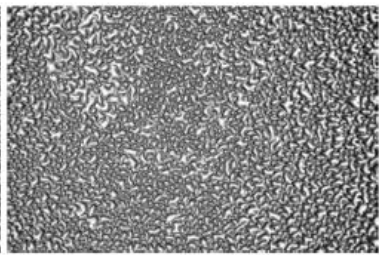

(h) $t=90 \mathrm{~min}$

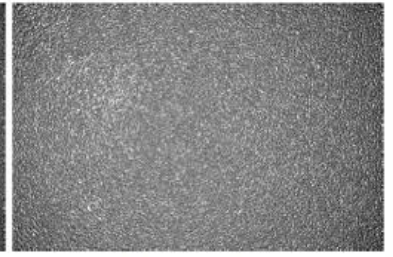

(c) $t=25 \mathrm{~min}$

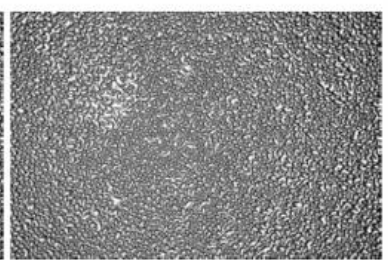

(f) $t=60 \mathrm{~min}$

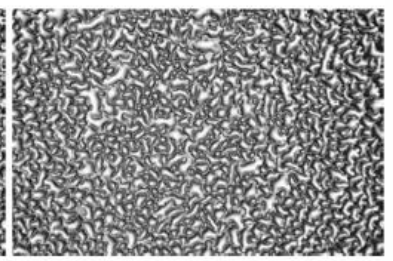

(i) $t=130 \mathrm{~min}$

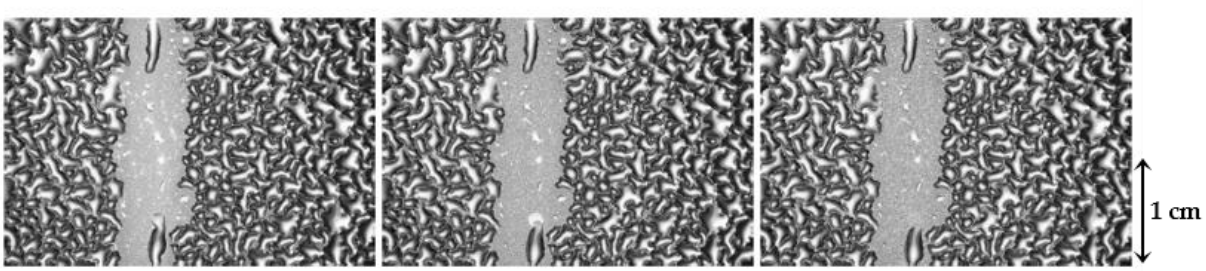

(m) $t=173 \mathrm{~min}$

(n) $t=180 \mathrm{~min}$

(o) $t=182 \mathrm{~min}$

Figure 10. Condensation growth mechanism

At time $\mathrm{t}=15 \mathrm{~min}$ (Figure $10 \mathrm{~b}$ ), the camera starts to perform a proper focus, as the droplets edges are clearly defined on the pictures. For this reason, this is also the moment for which the image series are used for post-processing. As the droplets become larger in size and as the distances between neighboring droplets become smaller, the coalescence effect begins. Smaller droplets fuse into bigger droplets. The coalescence process seems to be the dominating mechanism for the 
droplet growth since it lasts from $t=15$ min up until $t=171 \mathrm{~min}$ (from Figure $10 \mathrm{~b}$ to Figure 10 k), which means about two hours and a half.

Once the droplets reach a certain size, called "fall-off size", they roll off on the glazing surface. In fact, as the droplets grow by coalescence and reach the "fall-off size", the gravity forces exceed the capillary force within the droplets. They cause them to fall and sweep away other droplets in their path as it can be seen at the moment $\mathrm{t}=172 \mathrm{~min}$ (Figure $10 \mathrm{l}$ ). Just one minute later, at $\mathrm{t}=$ $173 \mathrm{~min}$, right at the freshly cleared glazing surface, new droplets form rapidly at the nucleation sites. The re-nucleation starts over and the growth process cycle repeats, next to the other droplets which still undergo the coalescence process (Figure $10 \mathrm{n}$ and Figure $10 \mathrm{o}$ ).

\subsection{Condensation rate quantification}

Results concerning the condensation rate obtained based on two theoretical models (Equation (5) [50] and Equation (6) [51]) and experimentally, using the image processing method developed in this study, are given in Figure 11. It should be mentioned that the time shown in the $\mathrm{x}$-axis is in perfect synchronization with all the previous graphs.

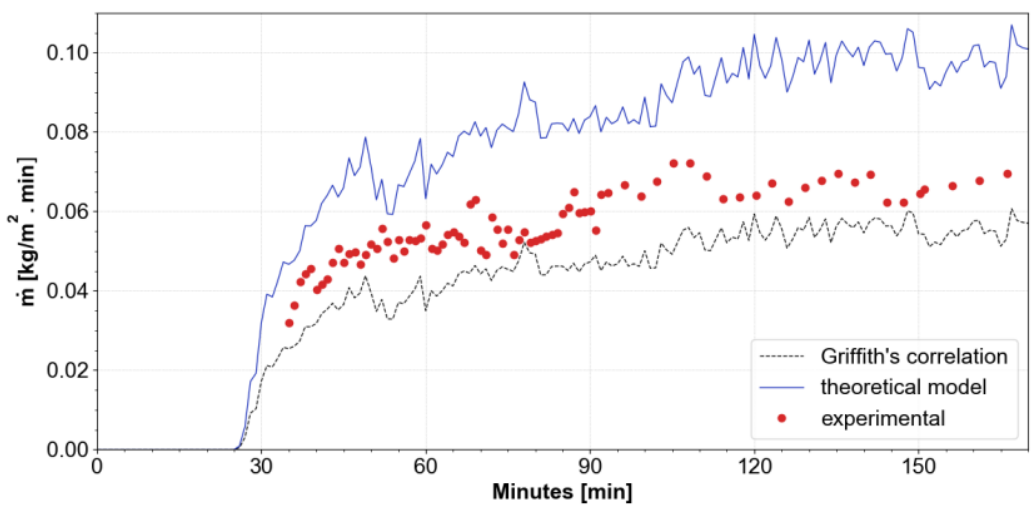

Figure 11. Evolution of the condensation rate

The values of condensation rate based on Griffith's correlation [50] were determined as follows: the overall heat transfer coefficient (Equation (5)) is computed using the vapor dew point temperature (presented in Figure 9) and its value is then introduced in Equation (3).

On the other hand, to determine the condensation rate using the theoretical model (Equation 6 [51]), the following data is needed: the droplet minimum radius $r_{\min }$, the droplet fall-off radius $r_{\text {max }}$ and the droplet contact angle $\theta$. The minimum radius $r_{\text {min }}$ is computed using the Equation (7). Based on Figure 9 1, the fall-off radius $r_{\max }$ is assumed to be equal to $2.0 \mathrm{~mm}$. The contact angle $\theta$ 
is assumed to be equal to $56.9^{\circ}$, which is an averaged value determined following the tests described in this study (see section 3.2.).

Based on Figure 11, it can be noticed that the condensation process begins exactly when the dew point temperature exceeds the glazing surface temperature (see also Figure 9). On the other hand, the condensation rate obtained from the theoretical model [51], Equation (6), is twice higher than the values issued from the Griffith's correlation [50], Equation (5). The comparison of the experimental results with the theoretical model [51] indicates a mean relative difference of approximately $18 \%$, which implies an overall good agreement.

Nevertheless, the uncertainty of the experimental data remains to be established as the method proposed in this study may include some error sources. One of the error source lies in the image binarization process. This step is crucial since finding droplet contours is based on binarized images. For one global thresholding method, it might be complicated to choose manually an optimal threshold value for each image. The adaptive thresholding methods are relevant choices for images with varying illumination (as we have done) but these methods require input parameters defined by the users and this may lead to some errors. Other error source is related to the image capturing process. The droplets are illuminated differently depending on their size. The more the droplets increase in size, the more the contour edges of the droplets are illuminated non-uniformly from one direction to another (Figure 10). Regardless of the thresholding method employed, there are still some droplet contours that cannot be properly connected. This has an impact on the precision of the results as these contours non-connected are not taken into account in the calculation of the condensation rate.

In addition, the condensation rate method proposed here requires the droplet volume or one of the main assumption of our data treatment has been that Equation (1) is also valid for droplets whose shape is not a perfect truncated sphere.

Consequently, further investigations are needed in order to clarify all these aspects related to the accuracy of the condensation rate quantification methodology developed in this work.

\section{Conclusions}

The method proposed in this work has led to promising results concerning the condensation rate quantification on cold glazing within ventilated rooms. Furthermore, this study confirms that 
image processing technique is a reliable method for analyzing the condensation process on glazed building elements.

In addition, the experimental results on the surface condensation rate presented in this study can be extremely valuable as there are no similar data in the literature for full-scale room. We also believe that the experimental method developed allows improving the current knowledge on the superficial condensation process. As a result, this method can have multiple technical and industrial applications: residential and commercial buildings (thermal comfort, indoor air quality and energy consumption); museums and industry (microclimate control and technological conditions, e.g. papermaking plants); vehicles (condensation and freezing prediction on the windshield).

The results from this paper can be also used to validate numerical data obtained from CFD simulations concering superficial condensation process. As a matter of fact, CFD numerical studies are ongoing for this, starting from previously developed models [33]. The numerical results obtained, as well as the comparison with experimental data, will be the subject of a future work.

Nevertheless, some future work is compulsory to consolidate the findings and extend the analysis based on the experimentally method presented here. For example, in order to improve the accuracy of the results, we suggest the following regarding the experimental apparatus: the whole camera system can be upgraded (the body and the lens, to get a higher resolution and a reproduction ratio greater than 1; the camera lens can be also replaced by a telescope); an additional camera can be considered in order to obtain information on the droplet contact angle (this camera needs to be set up at the glazing surface, perpendicularly with the direction of the growth of droplets, to capture this information).

At the same time, the accuracy of experimental results can be greatly improved by refining the image processing technique. This will be mainly possible due to the continuous and remarkable development of computer science.

\section{Acknowledgement}

This work was supported by a grant of the French Research Agency (ANR) and Romanian Ministry of Education and Research (CNCS-UEFISCDI), project number PN-II-ID-JRP-RO-FR2012-0071.

\section{References}


[1] R. Becker, Condensation and mould growth in dwellings-Parametric and field study, Build. Environ. 19 (1984) 243-250.

[2] M.D. Lawton, R.E. Dales, J. White, The influence of house characteristics in a Canadian community on microbiological contamination, Indoor Air 8 (1998) 2-11.

[3] B.M Small, Creating mold-free buildings: A key to avoiding health effects of indoor molds, Arch. Environ. Health Int. J. 58 (2003) 523-527.

[4] S. You, W. Li, T. Ye, F. Hu, W. Zheng, Study on moisture condensation on the interior surface of buildings in high humidity climate, Build. Environ. 125 (2017) 39-48, 10.1016/j.buildenv.2017.08.041

[5] B. Weinhold, A Spreading Concern: Inhalational Health Effects of Mold, Environmental Health Perspectives 115 (6) (2007) A300-A305, 10.1289/ehp.115-a300

[6] J.P. Zock, D. Jarvis, C. Luczynska, J. Sunyer, P. Burney, Housing characteristics, reported mold exposure, and asthma in the European Community Respiratory Health Survey, Journal of Allergy and Clinical Immunology 110 (2) (2002) 285-92.

[7] W.J. Fisk, Q. Lei-Gomez, M.J. Mendell, Meta-analyses of the associations of respiratory health effects with dampness and mold in homes, Indoor Air 17 (4) (2007) 284-96, 10.1111/j.16000668.2007.00475.x

[8] L. Casas, A. Espinosa, J. Pekkanen, A. Asikainen, A. Borras-Santos, J. Jacobs, E.J.M. Krop, M. Täubel, A. Hyvärinen, D. Heederik, J.P. Zock, School attendance and daily respiratory symptoms in children: influence of moisture damage, Indoor Air 27 (2) (2017) 303-10, 10.1111/ina.12311

[9] U. Haverinen, M. Vahteristo, J. Pekkanen, T. Husman, A. Nevalainen, D. Moschandreas, Formulation and Validation of an Empirical Moisture Damage Index, Environmental Modeling \& Assessment 8 (4) (2003) 303-309, 10.1023/B:ENMO.0000004583.93890.86

[10] H. Saito, K. Fukuda, T. Sawachi, Integration model of hygrothermal analysis with decay process for durability assessment of building envelopes, Build Simul. 5 (4) (2012) 315-24, 10.1007/s12273-012-0081-8

[11] AIVC Technical Note 20: 1987, Airborne Moisture Transfer: New Zealand Workshop Proceedings and Bibliographic Review, Air Infiltration and Ventilation Center, Paris, France, 1987. 
[12] IEA Annex XIV: 1991, Energy Conservation in Buildings and Community Systems Programme, Condensation and energy. Report Annex XIV, vol. 1, Sourcebook, International Energy Agency, Leuven, Belgium, 1991.

[13] IEA Annex XXIV: 1996, Heat, Air and Moisture Transport. Modelling - Final Report, vol. 1, Part 1, International Energy Agency, Leuven, Belgium, 1996.

[14] C. Rode, H. Hens, H. Janssen, IEA Annex 41 whole building heat, air, moisture response: Closing seminar, Nordic Building Physics Conference. BYG Rapport, No. R-191, Copenhagen, Denmark, 2008.

[15] ASHRAE handbook-fundamentals: 2017, American Society of Heating, Refrigerating and Air-Conditioning Engineers, Atlanta, GA, 2017.

[16] M. Woloszyn, Hygro-thermo-aeraulic modeling of multi-zone buildings. Proposal of a strategy for the resolution of the coupled system (in French), PhD. Thesis, INSA Lyon, Lyon, France, 1999.

[17] P. Plathner, M. Woloszyn, Interzonal air and moisture transport in a test house: experiment and modelling, Build. Environ. 37 (2) (2002) 189-199, 10.1016/S0360-1323(00)00096-2

[18] M. Woloszyn, T. Kalamees, M. O. Abadie, M. Steeman, A. Sasic Kalagasidis, The effect of combining a relative-humidity-sensitive ventilation system with the moisture-buffering capacity of materials on indoor climate and energy efficiency of buildings, Build. Environ. 44 (3) (2009) 515-524, 10.1016/j.buildenv.2008.04.017

[19] H.J. Steeman, M. Van Belleghem, A. Janssens, M. De Paepe, Coupled simulation of heat and moisture transport in air and porous materials for the assessment of moisture related damage, Build. Environ. 44 (10) (2009) 2176-2184, 10.1016/j.buildenv.2009.03.016

[20] M. Van Belleghem, H.J. Steeman, M. Steeman, A. Janssens, M. De Paepe, Sensitivity analysis of CFD coupled non-isothermal heat and moisture, Build. Environ. 45 (11) (2010) 2485-96, 10.1016/j.buildenv.2010.05.011

[21] M. Van Belleghem, M. Steeman, A. Willockx, A. Janssens, M. De Paepe, Benchmark experiments for moisture transfer modelling in air and porous materials, Build. Environ. 46 (4) (2011) 884-898, 10.1016/j.buildenv.2010.10.018

[22] M. Van Belleghem, M. Steeman, H. Janssen, A. Janssens, M. De Paepe, Validation of a coupled heat, vapour and liquid moisture transport model for porous materials implemented in CFD, Build. Environ. 81 (2014) 340-353, 10.1016/j.buildenv.2014.06.024 
[23] F. Tariku, K. Kumaran, P. Fazio, Integrated analysis of whole building heat, air and moisture transfer, Int J Heat Mass Transf. 53 (15-16) (2010) 3111-3120, 10.1016/j.ijheatmasstransfer.2010.03.016

[24] M. Qin, Whole-building heat, air, and moisture transfer modeling for residential buildings in different climates, HVAC\&R Research 17 (5) (2011) 860-871.

[25] W. Feng, J. Grunewald, A. Nicolai, C. Zhang, J.S. Zhang, CHAMPS-Multizone-A combined heat, air, moisture and pollutant simulation environment for whole building performance analysis, HVAC\&R Research 18 (1-2) (2012) 233-251.

[26] L. Pu, F. Xiao, Y.Z. Li, Z.J. Ma, Effects of initial mist conditions on simulation accuracy of humidity distribution in an environmental chamber, Build. Environ. 47 (2012) 217-222, 10.1016/j.buildenv.2011.07.020

[27] W. Cho, S. Iwamoto, S. Kato, Condensation Risk Due to Variations in Airtightness and Thermal Insulation of an Office Building in Warm and Wet Climate, Energies, 9 (11) (2016) 875, 10.3390/en9110875

[28] J., Liu, H. Aizawa, H. Yoshino, CFD prediction of surface condensation on walls and its experimental validation, Build. Environ. 39 (8) (2004) 905-911, 10.1016/j.buildenv.2004.01.015 [29] G.C. Gong, C.W. Xu, J.J. Jiao, Y.K. Liu, S.N. Xie, Investigation of moisture condensation on papermaking plant envelopes in high humidity environment by orthogonal analysis and CFD simulation, Build. Environ. 46 (8) (2011) 1639-1648, 10.1016/j.buildenv.2011.01.031

[30] S.J. You, W.Q.P. Li, T.Z. Ye, F. Hu, W.D. Zheng, Study on moisture condensation on the interior surface of buildings in high humidity climate, Build. Environ. 125 (2017) 39-48, 10.1016/j.buildenv.2017.08.041

[31] X.J. Ma, X.T. Li, X.L. Shao, X. Jiang, An algorithm to predict the transient moisture distribution for wall condensation under a steady flow field, Build. Environ. 67 (2013) 56-68, 10.1016/j.buildenv.2013.04.028

[32] C. Teodosiu, R. Hohota, G. Rusaouën, M. Woloszyn, Numerical prediction of indoor air humidity and its effect on indoor environment, Build. Environ. 38 (5) (2003) 655-664, 10.1016/S0360-1323(02)00211-1

[33] R. Teodosiu, Integrated moisture (including condensation) - Energy-airflow model within enclosures. Experimental validation, Build. Environ. 61 (2013) 197-209, 10.1016/j.buildenv.2012.12.011 
[34] ANR-UEFISCDI: 2016, Integrated heat-airflow-moisture model within enclosures. Experimental validation (HAM) - PN-II-ID-JRP-RO-FR-2012-0071, Agence Nationale de la Recherche, Paris, France/Executive Unit for Financing Higher Education, Research, Development and Innovation, Bucharest, Romania, 2016.

[35] C.K. Nguyen, Full-scale experimental characterization of a non-isothermal realistic air jet for building ventilation: local interaction effects and condensation prediction (in French), PhD. Thesis, INSA Lyon, Lyon, France, 2018.

[36] C.K. Nguyen, D. David, F. Kuznik, G. Rusaouën, Ceiling turbulent asymmetrical air jets under interaction effects of room architectural elements - a full-scale experimental characterization, Proceedings of Roomvent \& Ventilation, Espoo, Finland, 2-5 June 2018, p. 181186.

[37] M. Sandberg, Whole-Field Measuring Methods in Ventilated Rooms, HVAC\&R Research13 (6) (2007) 951-970.

[38] S. Datcu, L. Ibos, Y. Candau, S. Matteï, Improvement of building wall surface temperature measurements by infrared thermography, Infrared Physics \& Technology 46 (6) (2005) 451-467, 10.1016/j.infrared.2005.01.001

[39] F.P. Incropera, D.P. Dewitt, T.L. Bergman, A.S. Lavine, Fundamentals of heat and mass transfer (6 ${ }^{\text {th }}$ ed.), John Wiley, Hoboken, NJ, 2007.

[40] A. Faghri, Y. Zhang, Transport phenomena in multiphase systems (1 ${ }^{\text {st }}$ ed.), Elsevier Academic Press, Burlington, Mass, 2006.

[41] Kyowa Interface Science (2018), Measurement of the Contact Angle. Retrieved December 12, 2018, from http://www.facekyowa.co.jp/english/en_science/en_theory/en_what_contact_angle/ [42] D.Y. Kwok, A.W. Neumann, Contact angle measurement and contact angle interpretation, Advances in Colloid and Interface Science 81 (1999) 167-249, 10.1016/S0001-8686(98)00087-6 [43] J.C. Russ, F.B. Neal, The image processing handbook ( $7^{\text {th }}$ ed.), CRC Press, Boca Raton, FL, 2017.

[44] C. Tomasi, R. Manduchi, Bilateral filtering for gray and color images, Proceedings of the $6^{\text {th }}$ International Conference on Computer Vision, Bombay, India, 7 January 1998, p. 839-846, 10.1109/ICCV.1998.710815 
[45] S. Paris, P. Kornprobst, J. Tumblin, F. Durand, A Gentle Introduction to Bilateral Filtering and Its Applications, Proceedings of SIGGRAPH '07 ACM SIGGRAPH 2007 courses, San Diego, CA, 5-9 August 2007, Article no. 1, 10.1145/1281500.1281602

[46] Open Source Computer Vision (2018), Image Thresholding (OpenCV-Python Tutorials).

Retrieved May 30, 2018, from

https://docs.opencv.org/3.4.1/d7/d4d/tutorial_py_thresholding.html

[47] N. Otsu, A Threshold Selection Method from Gray-Level Histograms, IEEE Transactions on Systems, Man, and Cybernetics 9 (1979) 62-66, 10.1109/TSMC.1979.4310076

[48] Open Source Computer Vision (2018), Contours in OpenCV (OpenCV-Python Tutorials).

Retrieved May 28, 2018, from

https://docs.opencv.org/3.4.1/d3/d05/tutorial_py_table_of_contents_contours.html

[49] R.R. Rogers, M.K. Yau, A Short Course in Cloud Physics (3rd ed.), Pergamon Press, Oxford, UK, 1989.

[50] P. Griffith, Dropwise Condensation, in: E.U. Schlunder, Heat Exchanger Design Handbook ( $2^{\text {nd }}$ ed.), Hemisphere Publishing, New York, NY, 1983.

[51] S. Kim, K.J. Kim, Dropwise Condensation Modeling Suitable for Superhydrophobic Surfaces, J. Heat Transfer 133 (8) (2011) 081502,10.1115/1.4003742 